bring new ideas into the field. It would perhaps be a fair opinion to say that, although this book has little interest for the general practitioner as such, it has a great interest for doctors who are capable of constructive thought; and it may perhaps find its greatest field in helping those who specialise in gastro-intestinal diseases.

\section{SURGICAL DIAGNOSIS.}

By Stephen Power, M.S. (Lond.), F.R.C.S. (Eng.). John Wright \& Sons, Ltd., Bristol. 1939. Price 12s. 6d.

This book has been written with the idea of clinical diagnosis of most of the conditions met with in ordinary surgical practice. Like most books of this kind, it is not (and cannot be) an exhaustive survey of all the avenues to diagnosis, nevertheless the author has managed to cover an extensive ground in a small space. The book should be useful to students and surgeons, and, as such, is to be commended.

\section{PRECLINICAL MEDICINE.}

By Malford W. Thewlis. Baillière, Tindall \& Cox, 1939. Price 13s. 6d.

I suppose it has occurred to many physicians of repute that it might be a good thing out of their growing experience to write a book giving some indication as to how a disease may be recognised before it gives such obvious indications that anyone may recognise it. Dr. Thewlis has put this thought into practice. It is, of course, well known that certain clinical states either follow on or are caused by definite well known syndromes. For instance, bronchiectasis sometimes follows whooping cough. Therefore, if whooping cough can be prevented, the incidence of bronchiectasis should fall. Such things as these are well brought out by Dr. Thewlis and, of course. mention is made of the fact that poor grade individuals should not go into hazardous industries.

It is really doubtful whether such simple things as these really require a book to themselves and so one turns to diseases the very early detection of which is of prime importance, and naturally thought is directed to the question of cancer. In the chapter on cancer, hereditary factors and racial predisposition are considered; carcinogenic factors are mentioned and the role played by oestrin is mentioned. Statistical tables are attached. The question of obesity is given place and various pre-cancerous conditions are listed.

Taking cancer of the lung as one of the great problems of the day, the suggestion is made that excessive use of tobacco, tuberculosis and chronic bronchitis may be causes. The question of tarred roads and petrol fumes are mentioned and the suggestion is made that high voltage $\mathrm{X}$-ray therapy improves the condition when detected.

From these very brief extracts it will be seen that it is difficult to allocate a place for this book. Naturally it tells nothing new, but further than this it does not seem to provide the information which the reader is entitled to expect after perusal of this title. There are many physicians of experience who could write a book on this subject which would be full of interest, for such a book should give experiences and observations which are not available in ordinary textbooks of medicine and which only come from prolonged experience.

\section{THE CONJOINT FINALS.}

By Gerald N. BeEston, M.R.C.S., L.R.C.P. 3rd Edition. John Bale, Sons \& Curnow. 1939. Price 10s. 6d.

This book is a reproduction of all the questions set in the Conjoint Finals from 1911-1937, classified and arranged in date order of their occurrence, together with the classification of questions on pathology and bacteriology set as separate papers since 1930 .

\section{TOMOGRAPHY.}

By J. B. MacDougall, M.D., F.R.C.P., F.R.S. H. K. Lewis \& Co., 1940. Price 21s. Od.

Dr. MacDougall is one of the pioneers of the tomograph in this country and has published the results of his research in this book. The book starts with a discussion of the principles which underlie the tomograph and the technique employed. It is very fully illustrated, several tomographs on each page, and it is the most complete thing of its sort that has even been published in this country.

The pictures as a whole are extremely good and perhaps especially interesting are those pictures showing $\mathrm{X}$-rays of the chest on one side with a suitable tomographic section to illustrate the essential lesion on the other. For instance, several of them show quite clearly the exact constriction in a bronchus produced by a carcinoma. Others, especially those dealing with thoracoplasty, show how deceptive a straight $\mathrm{X}$-ray can be for the tomograph shows large cavities still existing.

Some of the work has been done by Dr. MacDougall's two assistants, Dr. J. H. Crawford and Dr. A. Ross.

It would not be an exaggeration to say that everyone who is interested in chest medicine or surgery would do well to buy and study this work.

\section{UTERIS MASCULINUS.}

By J. A. Leo Magee. H. K. Lewis \& Co. 1939. Price 5s. 0d.

This book must really be read to be appreciated. It is only a very short book. It. deals with the anatomy and embryology of the prostate gland and makes original, and perhaps to some startling, suggestions. It is stated quite frankly that the views expressed in the book are personal and amount to a conviction.

To anyone who is interested in this problem. it might be of advantage to obtain a new outlook. 